HELMINTHOLOGIA, 52, 4: 316 - 322, 2015

\title{
Cathaemasia hians infection in Black stork in Slovakia: morphological and histopathological study
}

\author{
A. KÖNIGOVÁ ${ }^{1 *}$, G. HRČKOVÁ1* , L. MOLNÁR², P. MAJOR², M.VÁRADY1 \\ ${ }^{1}$ Department of Experimental Pharmacology, Institute of Parasitology, Slovak Academy of Sciences, Hlinkova 3 , \\ Košice, 04001, Slovakia, ${ }^{*}$ E-mail: konig@saske.sk, hrcka@saske.sk; ${ }^{2} \mathrm{Clinic}$ for Birds and Exotic Animals, University of Veterinary \\ Medicine and Pharmacy Komenského 73, 041 81, Košice, Slovakia
}

\section{Article info}

Received May 28, 2015 Accepted June 24, 2015

\begin{abstract}
Summary
Cathaemasia hians is an obligate trematode parasite of Black storks that are on the List of protected birds in Europe. In the present study, adult trematodes were isolated from the Black stork post mortem and morphological study revealed C. hians species. In total, 10 worms were found in the oesophagus and the ventriculus of the bird. Histopathological examination of the tissue samples of oesophagus, proventriculus and ventriculus was performed on paraffin sections using a set of staining procedures. The sporadic lesions were seen in the tela submucosa of oesophagus containing connective tissue mast cells, eosinophils and heterophils and some foci were surrounded by the fibrous tissue. In addition, a few inflammatory nodules had larval-like material inside, probably being of the same species. There were no visible morphological alterations in the epithelial layer of lamina propria mucosae of proventriculus, rich in goblet cells as well as in the tela submucosa. Majority of trematodes were localized in the ventriculus, where the lamina propria mucosae was damaged or disrupted sporadically. In these sites, in the tela submucosa, a various food-originated inorganic/organic material and eggs of $C$. hians were deposited, stimulating a weak inflammatory response. Nodules containing larvae were not observed in any of ventriculus tissue layers. This study demonstrated, for the first time, infection with adults of $C$. hians trematode in the Black stork nesting in Slovakia. The presence of larvae and eggs in the tissues of the upper gastrointestinal tract of bird was associated with mild inflammatory response but feeding behaviour of adult worms in the ventriculus probably contributed to the enhanced susceptibility of the lamina propria mucosae to mechanical damage by inorganic material. Although larval stages have not yet been documented in the intermediate hosts in Slovakia, our report indicates that the life cycle of $C$. hians might occur in Central Europe.
\end{abstract}

Keywords: Black stork; Cathaemasia hians; trematode; gastrointestinal tract; histopathology

\section{Introduction}

The Black stork, Ciconia nigra Linnaeaus, 1758, a wading bird in the stork family Ciconiidae, is an endangered species of migratory water birds. Black storks migrate from Europe to Africa via two routes. The western route goes through France, Spain and Gibraltar, though many birds take the Eastern route through Hungary, Romania, Bulgaria, Bosporus to Asia Minor and pass the Suez Canal to South Africa (Karaska, 2002). The species has Palearctic distribution in Europe, with its highest occurrence in the Baltics,
Belarus, Poland and Slovakia (IUCN, Red List Category). The estimated number of nesting black storks in Europe is from 7800 to 12000 , while the number of breeding pairs is estimated to be from 400 up to 600 (Karaska, 2002). In Europe this species is on the list of protected animals.

The occurrence of trematodes of the family Cathaemasiidae has been confirmed in the stork family Ciconiidae during spring migration and nesting in eastern and southern Europe (Merino et al., 2001; Karaska, 2002; Liptovszky et al., 2012; Sitko \& Heneberg, 2015). The family Cathaemasiidae Fuhrmann, 1928 comprises 
two fluke subfamilies, five genera and 20 species (Kostadinova, 2005). The species of Cathaemasia genus are typical parasites found in the gastrointestinal tract of the White stork (Ciconia ciconia) and the Black stork (Ciconia nigra). In Slovakia, Macko (1960) has identified morphologically the juvenile stages of subspecies $C$. hians longivitella in the White storks and $C$. hians hians in the Black storks. Black storks can be more likely infected with $\mathrm{C}$. hians than can White storks, due to their different feeding behaviour (Merino et al., 2001). White storks feed mainly in dry permanent pastures (Carrascal et al., 1993) and their diet is based on the arthropods and earthworms (Alonso et al., 1991). In contrast, Black storks feed on frogs, salamanders, amphibians, fish and molluscs, which live in the swamps and slow-flowing waters (Merino et al., 2001; Liptovszky et al., 2012; Zhytova \& Korol, 2012). The life cycle of C. hians (Rudolphi, 1809) involves molluscs of the family Planorbidae and Lymnaeidae, representing the first intermediate hosts, however in Central Europe cercaria of $C$. hians have been confirmed only in the great pond snail Lymnaea stagnalis and the ram's horn snail Planorbis planorbis in Poland, the Czech Republic and Ukraine (Grabda-Kazubska et al., 1990; Faltýnková et al., 2008;
Zhytova \& Korol, 2012). Flukes can elicit irreversible alterations in the tissues of digestive system of definitive hosts thus lowering the fitness of the birds. Although trematode infections in the wild birds appear to cause little stress to a healthy host, the parasites can cause serious health problems when massive parasite infection is combined with other factors, such as cachexia or lower immunity of the hosts (Okulewicz \& Sitko, 2012; Königová et al., 2013; Santoro et al., 2013). In terms of malnutrition and cachexia in heavy trematode infections, histopathological changes play an important role in the function of digestive system of the bird hosts, as the intensity of parasitic infection directly affects physiological digestion. The studies referring to histopathological changes in the digestive system in wild birds as a result of parasitic infection are rather scarce. In addition, wild birds can be obtained usually at various periods post mortem what hampers specific histological evaluations of tissues (Hurníková et al., 2014).

In this study the morphological description of C. hians adults isolated from the injured Black stork found in Eastern Slovakia is provided along with histopathological analysis of the upper part of the bird's digestive system.
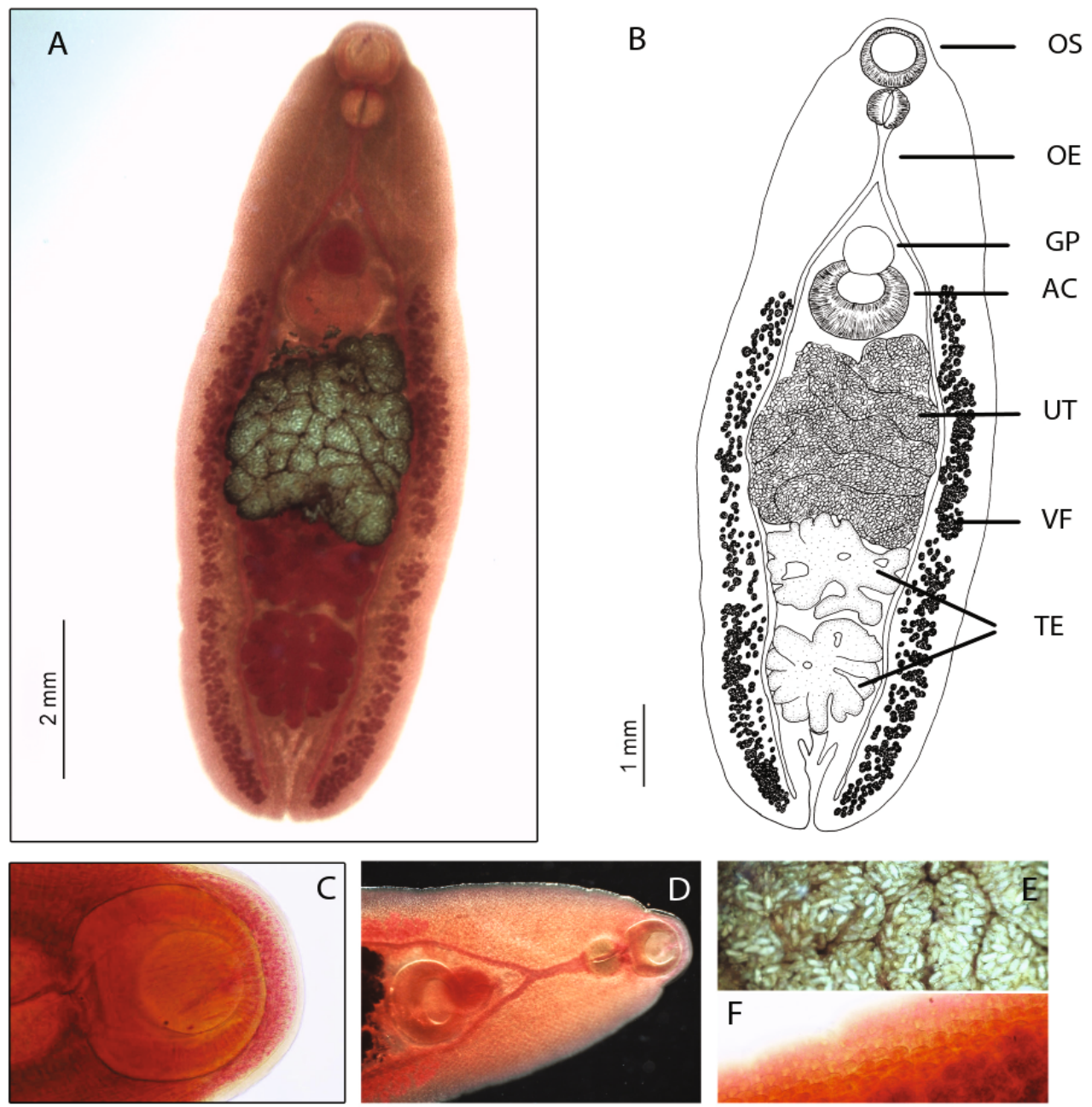

Fig. 1 (A-F). Morphological characteristics of adult Cathaemasia hians. A, image of the specimen following fixation and staining with Semichon's carmine.

B, schematic representative image showing detailed morphology of trematode: OS, oral sucker; OE, oesophagus; GP, genital pore; AC, acetabulum; UT, uterus; VF, vitelline follicles; TE, testes. C, the oral sucker with a strong musculature. D, detail of the anterior part of digestive system, $E$, the uterus with the mature eggs and $\mathrm{F}$, the blunt scales covering tegument 


\section{Material and Methods}

The malnourished adult male Black stork was found with a broken wing in the area of Eastern Slovakia. It did not survive surgery. During the necropsy, adult trematodes were collected from the oesophagus and the ventriculus and were fixed in the mixture of hot $10 \%$ neutral formalin and $70 \%$ alcohol according to the procedure described previously by Chernogorenko (1983). One specimen was used for sectioning after proceeding for paraffin sections. The rest of flukes were then stained by Semichon's carmine, cleared in the clove oil (Sigma-Aldrich, USA), mounted on slides in the Canada balsam and subjected to the morphometric and morphological analyses. Identification of the flukes was based on the morphological features delineating the species of the family Cathaemasiidae (Kostadinova, 2005).

During the necropsy, the samples of oesophagus, proventriculus and ventriculus were removed from the bird and processed for histological examinations. The longitudinal sections were prepared from each organ and were fixed for 72 hours in $4 \%$ paraformaldehyde solution (PFA) in PBS (pH 7.4) at $4^{\circ} \mathrm{C}$. After fixation, tissues were dehydrated in the graded alcohols, cleared in xylene and embedded in paraffin wax. The tissue sections $(5-7 \mu \mathrm{m})$ were prepared and subjected to several staining procedures. At first, sections from all tissues were stained with haematoxylin and eosin (HE) stains. Connective tissue mast cells (CTMC), the granules of which were seen in pink colour, were visualized following Toluidine blue staining. Eosinophils (Eo) were localized by means of the purple colour of their granules following the modified protocol using Harrison hematoxylin and alkaline Sirius red (Meyerholz et al., 2009). On formalin-fixed, paraffin-embedded tissue sections, Alcian blue staining was used to visualize the goblet cells, which were seen as the light blue granules (Enerback, 1966). For the visualization of the extracellular matrix proteins (EMC) including the collagens, which are typically associated with the chronic granulomatous tissue lesions, sections were stained with Picrosirius red for detection of EMC and Fast green stain, as was described previously (Hrčková et al., 2010). Morphometric analyses on the tissue sections as well as on parasitic specimen were performed using an Olympus Microscope BX51 and a Digital Analysis Imaging system „Analysis docu” (Czech Republic).

\section{Results}

\section{Necropsy and morphological analysis of parasites}

Parasitic infestation was also confirmed during the necropsy in the lover oesophagus and ventriculus ridges with the intensity of infection of 10. Parasites were isolated and processed for morphological and morphometric analyses. The criteria for identification of this trematode species were the shape and size of worms, appearance of cuticle, shape and localization of two suckers, digestive and reproductive systems, all shown previously (Kostadinova, 2005). The worms were finally delineated as trematode $C$. hians (Rudolphi, 1809) (Fig. 1A, B). The detailed morphological description of the adult parasites isolated from the Black stork is also presented in this study due to the absence of similar drawings in related reports. The body of worms was flattened and the mean length of the worms was $9940 \pm 1700 \mu \mathrm{m}$, breadth was $2500 \pm$ $650 \mu \mathrm{m}$ and width was $3480 \pm 880 \mu \mathrm{m}$. The mouth was situated at the anterior end of the oral sucker (OS) (diameter $760 \pm 120$ $\mu \mathrm{m})$ having strong annular and radial muscles (Fig. 1C). The ventral sucker (acetabulum, AC) was very muscular, spherical with a diameter of $1120 \pm 400 \mu \mathrm{m}$ localized in the anterior half of the body. Digestive track of the worms formed the short pre-pharynx, the muscular pharynx, the simple oesophagus (OE) and bifurcate intestine (Fig. 1D), what ended in cul de sac. The uterine channel (UT) was filled with the numerous fully developed eggs (Fig. 1E). Paired testes (TE) were branched and localised in the tandem close to caecum. The ovaries, placed in the front of the testes, as
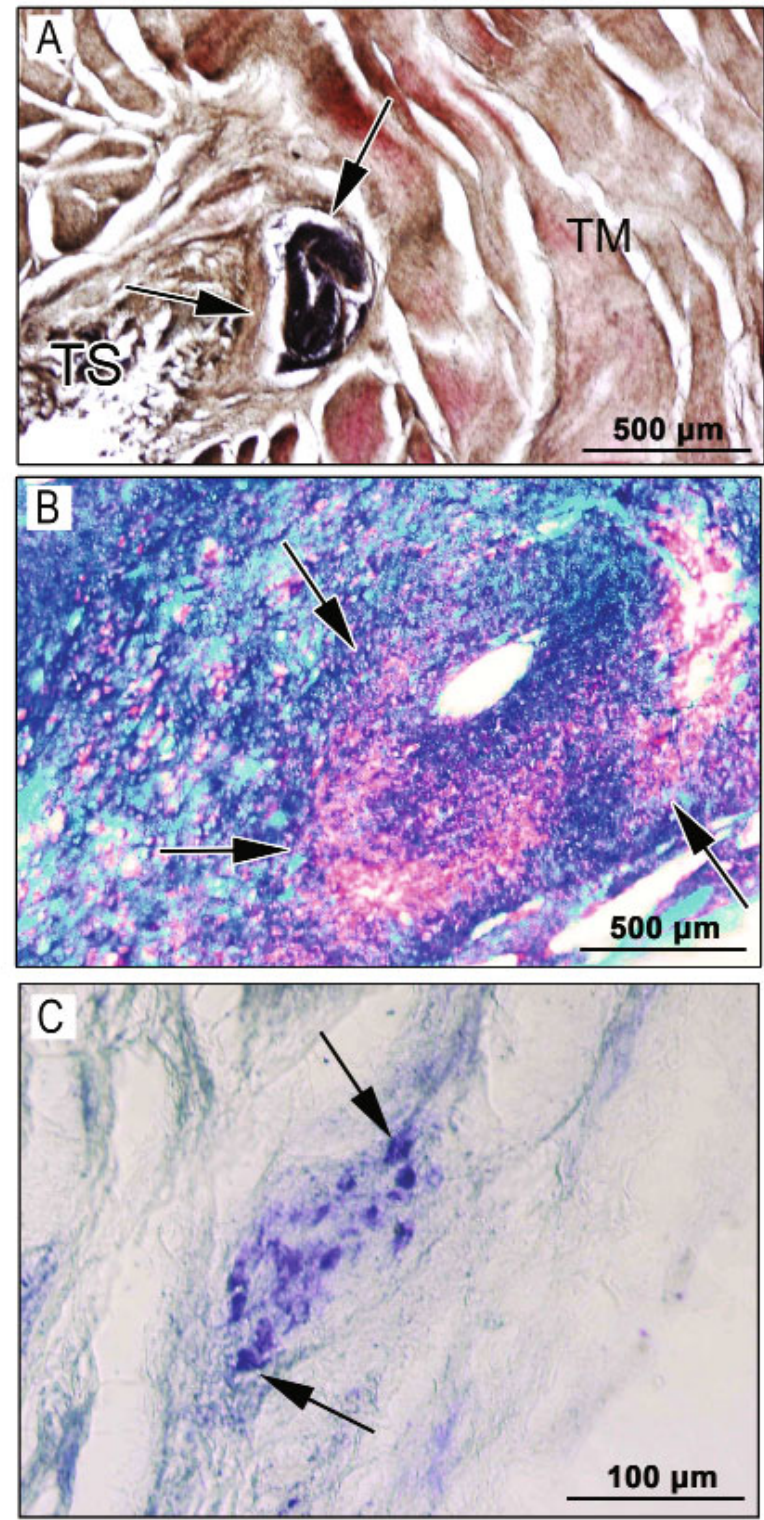

Fig. 2 (A-C). Representative microphotographs of the oesophagus tissue sections following specific staining.

$\mathrm{A}$, lesion with larval-like material in the muscular layer of oesophagus (arrows) localised between the tela submucosa (TS) and tunica muscularis (TM) (HE staining). B, granulomatous inflammatory lesion in the tissue of oesophagus containing the extracellular matrix proteins and collagens (arrows) (Picrosirius $\mathrm{red} /$ Fast green staining). $\mathrm{C}$, small inflammatory lesion with connective tissue mast cells in the tela submucosa of oesophagus (arrows) (Toluidine blue staining) 
well as the Mehlis' glands (vitelline follicles, VF), were not seen, as the ascending limb of uterus overlapped them. Blunt scales were covering tegument on the ventral surface of the body (Fig. 1F).

\section{Histological examination of the digestive system of bird}

In the oesophagus of the bird, the photophobic adults of $C$. hians were observed, moving towards the lower parts of the digestive system. Histopathological examination did not reveal any damage to the epithelium due to migration of trematodes. Following $\mathrm{HE}$ staining of the sections of oesophagus, nodules containing larva were localized between the tela submucosa and muscle layers but their species identification was not possible. They were enclosed in the fibrous material and size of lesions and the appearance of larvae suggested that they might be of the same species (Fig. $2 \mathrm{~A})$. Some of them were surrounded by the layers of extracellular matrix proteins, mainly collagens, which are typical for the late, chronic inflammatory lesions (Fig. 2B). In some of these lesions, in the tela submucosa and the tunica muscularis, a few connective tissue mast cells were localized (Fig. 2C), whereas they were not seen in the lesion-free tissue samples. Heterophils and eosinophils occurred only sporadically in vicinity of nodules with larva. Goblet cells and their product mucin were observed scarcely in the glands formed by cuboidal cells in the lamina propria mucosae. Neither larvae, nor inflammatory reactions were observed in the proventriculus.

Histopathological changes were also confirmed in the ventriculus, where most of the adult specimen were found (Fig. 3A). Integrity of the epithelium and the lamina propria mucosae was damaged or disrupted in some sites, where various inorganic (Fig. 3B) or organic materials (Fig. $3 \mathrm{C}$ ), so called grit, were deposited. The eggs were found in the deeper layers of lamina propria mucosae in the sites of disrupted surface containing goblet cells (Fig. 3D, E). To confirm that they are of the same species, adult specimen was sectioned and eggs found in the uterus were stained and measured. They had clearly the same size and appearance (Fig. F). The layer of lamina propria mucosae is typically very rich in glands
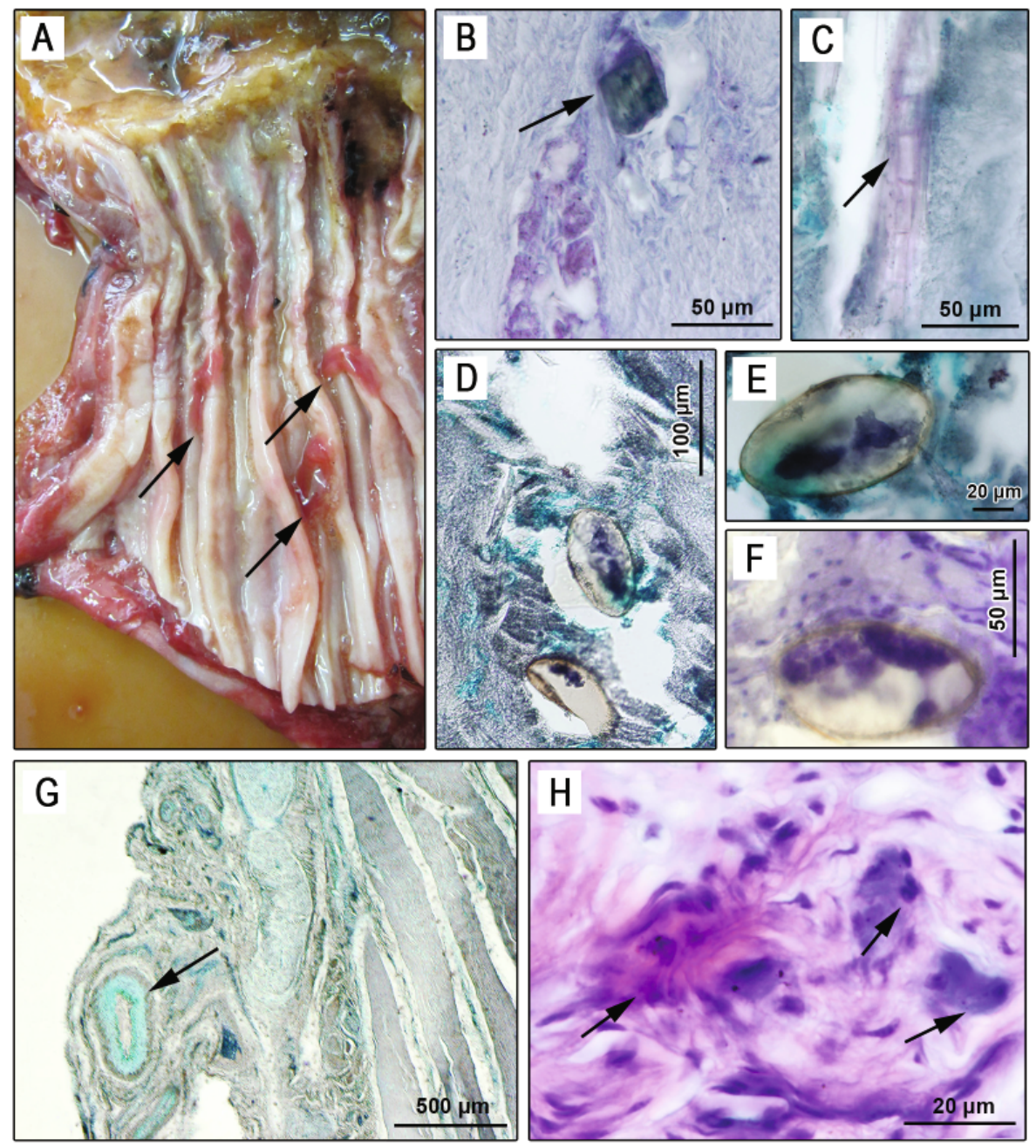

Fig. 3 (A-H) Images of the infected ventriculus of examined Black stork. A, the fluke specimens attached to surface of ventriculus (arrow).

$\mathrm{B}$, the inorganic grit in the lamina propria mucosae (arrow) (Harrison hematoxylin and alkaline Sirius red staining). $\mathrm{C}$, the organic grit in the lamina propria mucosae (arrow) (Harrison hematoxylin and alkaline Sirius red staining). D, E The eggs found in the lamina propria mucosae of ventriculus (arrows) (Alcian blue staining).

$\mathrm{F}$, The eggs detected in the uterus of adult $\mathrm{C}$. hians on the paraffin section (Toluidine blue staining). $\mathrm{G}$, Goblet cells in the glands in the lamina propria mucosae of ventriculus (arrow) (Alcian blue staining). $\mathrm{H}$, The infiltrations of heterophiles with rare eosinophils in the tela submucosa of ventriculus (arrows) (Harrison hematoxylin and alkaline Sirius red staining) 
containing goblet cells but large inflammatory lesions were not seen (Fig. 3G). However, small infiltrations of heterophiles with scarce eosinophils were observed in all layers of the ventriculus, in particular in the tela submucosa (Fig. $3 \mathrm{H}$ ) and between the tela submucosa and the tunica muscularis, but the presence of connective tissue mast cells was not confirmed.

The intestine was not available for histological analyses.

\section{Discussion}

This study deals with the adult $C$. hians infection in the specific bird host Black stork (Ciconia nigra) and the histopathological changes in the upper gastrointestinal (GI) system of infected bird. The Black stork is the stork species that has been little studied. Many aspects of its feed utilization and parasitostatus of GI tract are not known or were only partly investigated. Even detailed information on the populations of this species throughout its distribution range is neglected, mainly because Black storks breed in dense wood areas where accurate nesting surveys are difficult to carry out and this bird species is included in the List of protected animals in Europe. Living animals can only be found after sustaining serious injuries, as was the case of the animal examined in our study. It did not survive operation and cachexia was proposed to be responsible for the low fitness of the bird.

Although C. hians is well known as a parasite of the storks, reports on its occurrence and prevalence of infection in the wild storks in Europe are scarce. Adult $C$. hians infections in Black storks were reported also from the neighbouring Hungary by several authors (Sey, 1965; Edelényi, 1974; Liptovszky et al., 2012). Merino et al. (2001) described infection with C. hians in the injured adult Black stork and later in the juvenile nesting storks (Ciconia nigra) in Spain. C. hians trematodes were also described in the White storks (Ciconia ciconia) nesting in Germany (Schuster et al., 2002), where no information is available about the occurrence of this species in the Black storks.

The anterior portion of the avian GI tract is adapted for ingestion, storage and partial digestion of starch and proteins and damage to gastrointestinal epitelium may decrease nutrient absorption (Turk, 1982). However, there is very little information about the extent of damage and histopathological changes in digestive system in the stork species due to the adult and larval trematode infections. In general, they are considered as non-pathogenic to family Ciconiidae, when the intensity of parasitic infection in digestive tract is low, but infection may be linked to the cachexia, when the high number of adults parasitize. The large number of specimens of trematode Chaunocephalus ferox discovered in a White stork from the southern Italy and the resulting intestinal pathological changes probably inhibited absorption of the nutrients, leading to the cachectic status, a bleeding and eventual death of bird (Santoro et al., 2013). In Spain, the same trematode species was found in a group of white storks with similar intensity of infection as in our report (Höfle et al., 2003). Authors assumed that an alterations in digestive system of infected birds were responsible for the lower body weight in storks without lesions. Consequently, a single massive parasitic infection in a bird can cause serious health problems with the subsequent death, mainly when is combined with other factors, such as bacterial infection or injury. On the other hand, Okulewicz and Sitko (2012) in their study on the various wild bird species found post mortem, suggested that small-sized intestinal parasites are less dangerous for free ranging birds, even they are numerous.

Information about intensity of an adult trematode infection and resulting histopathological changes of the upper digestive system of stork species are very scarce. In the present study, the tissue samples of oesophagus, proventriculus and ventriculus have been sectioned and examined. We applied several histochemical staining methods used routinely for detection and distribution of inflammatory cells in the mammals and also for the localisation of extracellular matrix proteins. A few larvae were seen between the tela submucosa and the muscle layers in oesophagus, which probably represented encysted cercaria of the same species fed by the bird with infected first intermediate hosts. They were sometimes localized in the fibrous nodules, which are typical for the chronic stage of inflammatory response (Reeves \& Friedman, 2002). Histopathological analysis of the oesophagus revealed sporadic inflammatory lesions of various size containing connective tissue mast cells, heterophils and eosinophils, but visible damage to the epithelial layer was not observed. Eosinophils are involved in the immune response to the helminths and connective tissue mast cells were shown to participate in the immune-dependent formation of the fibrous lesions in the various tissues following injury (Henz et al., 2001). In the proventriculus, there were numerous glands, lumen of which was formed by the goblet cells, positively stained for mucin. We did not detect adult $C$. hians in this part of the $\mathrm{Gl}$ system and no larvae and inflammatory cells were observed in the tissue layers. Goblet cells are glandular simple columnar epithelial cells whose function is to secrete mucin. It dissolves in water to form mucus which covers the epithelial surface of digestive tract organs as protective barrier against harmful component and as a medium for microorganisms (Ding et al., 2011). This material probably prevents damage to the surface by the parasites. However, the majority of adult specimens were found in the ventriculus, where also integrity of the epithelium and the lamina propria mucosae was damaged or disrupted. In these sites inorganic and organic material and the eggs of $C$. hians were deposited but they did not elicit strong inflammatory response. Only small infiltrations of heterophiles and eosinophils were observed in the all layers of ventriculus, particularly in the tela submucosa. The duodenum was not examined but infection and tissue damages are possible to occur. Santoro et al. (2013) examined tissue response to the infection with flukes Chaunocephalus ferox in the White stork and they found nodular lesions in the duodenal mucosa. Infection often resulted in the loss of duodenal villi, necrosis or fibrosis and enlargement of intestinal crypts, whereas in the intestinal submucosa larvae were surrounded by the inflammatory infiltrates.

Black storks survive the winter period in Africa, where they usually become infected. In Europe, infection with larvae of $C$. hians was confirmed in the snails - the first intermediate hosts, in the Czech Republic (Faltýnková et al., 2008), but not yet in Slovakia. However, the presence of the mature adult trematodes in the examined Black stork containing numerous developed eggs which are released to the environment, as well as the presence of remnants 
of cercaria in the tissue of bird, indirectly suggests that the life cycle of this trematode occurs also in the Central Europe. Migrating birds infected with adult $C$. hians can serve as a potential source of parasitic infection during their spring migration to nesting localities, including Europe. Alternatively, passive transfer of the highly motile flukes from the oesophagus of infecting adult storks to nestlings may occur during the feeding.

In conclusion, this study demonstrated for the first time infection with adults of trematode $C$. hians in the Black stork nesting in Slovakia. The presence of larvae and eggs in the tissues of upper gastrointestinal tract of the bird was associated with mild inflammatory response but feeding behaviour of adult worms in the ventriculus probably contributed to the enhanced susceptibility of the lamina propria mucosae to mechanical damage by inorganic material. In case of high intensity of infection, the tissue damage and inflammation may contribute to the malnutrition and consequently low fitness in the stork family Ciconiidae.

\section{Acknowledgments}

This study was supported by Grant Agency VEGA No.2/0151/13, VEGA No. 2/0150/13. The publication has been realized within the frame of the project Centre of Excellence for Parasitology (Code ITMS: 26220120022) based on the support of the Operational Programme "Reserch \& Development" funded from the European Regional Development Fund (rate: $0.25 \%$ ). Authors thank to Dr. Marta Špakulová, Dr. Marek Renčo, and Dr. Zuzana Vasilková for technical assistance with specimens preparation and identification.

\section{Conflict of Interest}

There is no conflict of interest.

\section{References}

Alonso, J.C., Alonso, J.A., Carrascal, L.M. (1991): Habitat selection by foraging white storks, Ciconia ciconia, during the breeding season. Can. J. Zoology, 69: 1957 - 1962. DOI: 10.1139/z91-270 Carrascal, L.M., Bautista, L.M., LÁzaro, E. (1993): Geographical variation in the density of the white stork Ciconia ciconia in Spain: influence of habitat structure and climate. Biol. Conserv., 65: 83- 87 Ding, B.A., Pirone, A., Lenzi, C., Xiaoming, N., Baglini, A., Romboli, I. (2011). Histochemical features of the Muscovy duck small intestine during development. Tissue Cell, 43: 190 - 195. DOI:10.1016/j. tice.2011.03.001

EdelÉnYI, B. (1974): Trematodes II., Fauna Hungariae 117. Akadémiai Kiado, Budapest, 224

ENERBACK, L. (1966). Mast cells in rat gastrointestinal mucosa. I. Effects of fixation. Acta Pathol. Microbiol. Scand., 66: 289 - 302.

FaltÝnKovÁ, A., NAšıncovÁ, V., KablÁsKovÁ, L. (2008): Larval trematodes (Digenea) of planorbid snails (Gastropoda: Pulmonata) in central Europe: A survey of species and key to their identification. Syst. Parasitol., 69: 155 - 178. DOI: 10.1007/s11230-007-9127-1 Grabda-Kazubska, B., Bayssade-Dufour, C., Kiseliene, V. (1990): Chaemotaxy and excretory system of Echinocercaria choanophila
U. Szidat, 1936, a larval form of Cathaemasia hians (Rud., 1809) (Trematoda, Cathemasiidae). Acta Parasitol. Pol., 35: 97 - 105 Henz, B.M., Maurer, M., Lippert, U., Worm, M., Babina, M. (2001): Mast cells as initiators of immunity and host defense. Exp. Dermatol., 10: 1 - 10. DOI: 10.1034/j.1600-0625.2001.100101.x Höfle, U., Krone, O., Blanco, J.m., Pizzaro, M. (2003): Chaunocephalus ferox in free-living white storks in Central Spain. Avian Dis., 47: 506 - 512. DOI: 10.1637/0005-2086(2003)047[0506:CFIFWS]2.0. $\mathrm{CO}: 2$

HrČKovÁ, G., Velebný, S., SolÁr, P. (2010): Dynamics of hepatic stellate cells, collagen types I and III synthesis and gene expression of selected cytokines during hepatic fibrogenesis following Mesocestoides vogae (Cestoda) infection in mice. Int. J. Parasitol., 40(2): 163 - 174. DOI: 10.1016/j.ijpara.2009.06.008

Hurníková, Z., HrčKová, G., Agren, E., Komorová, P., Forsman, J., Chovanová, B., Molnár, L., Letková, V. (2014). First finding of Trichinella pseudospiralis in two Tawny Owls (Strix aluco) from Sweden. Helminthologia, 50(3): 190 - 197. DOI: 10.2478/s11687014-0228-5

Chernogorenko, M.I. (1983): Larval trematodes in molluscs of the Dnieper River and its reservoirs. Kyiv: Nauk dumka, 212

KARASKA, D. (2002): Bocian čierny (Ciconia nigra). In: Danko, Š., Darolová, A., Krištín, A. (Eds) Rozšírenie vtákov na Slovensku. Bratislava, Slovakia: Veda, pp. 688

Königová, A., MolnÁr, L., HrČKová, G., VÁRAdy, M. (2013). The first report of serraspiculiasis in Great Tit (Parus major) in Slovakia. Helminthologia, 50(4): 254 - 260. DOI: 10.2478/s11687-0130138-y

Kostadinova, A. (2005): Family Cathaemasiidae Fuhrmann, 1928. In: Jones, A., Bray, R.A., GiBSON, D.I. (Eds) Keys to the Trematoda. Volume 2. London, UK: CABI Publishing and The Natural History Museum, pp. $69-73$

Liptovszky, M., Majoros, G., Perge, E. (2012): Cathaemasia hians in a Black Stork (Ciconia nigra) in Hungary. J. Wildl. Dis., 48(3): 809 - 811. DOI: 10.7589/0090-3558-48.3.809

MACKO, J.K. (1960): On the fauna of plathelminthes of Black stork - Ciconia nigra. L. Biologia, 7: 549 - 552

Merino, S., Martinez, J., Lanzarot, P., Cano, L.S., Fernandez-GarCiA, M., Rodriguez-CaAbeiro, F. (2001): Cathaemasia hians (Trematoda: Cathaemasiidae) infecting Black Stork nestlings (Ciconia nigra) from central Spain. Avian Pathol., 30: 559 - 561. DOI: 10.1080/03079450120078761

Meyerholz, D.K., Griffin, M.A., Castilow, E.M., Varga, S.M. (2009). Comparison of histochemical methods for murine eosinophil detection in an RSV vaccine-enhanced inflammation model. Toxicol. Pathology, 37: 249 - 255. DOI: 10.1177/0192623308329342

Okulewicz, A., Sitko, J. (2012): Parasitic helminthes - probable cause of death of birds. Helminthologia, 49(4): 241 - 246. DOI: 10.2478/s11687-012-0045-7

Reeves, H.L., Friedman, S.L. (2002): Activation of hepatic stellate cells - a key issue in liver fibrosis. Front. Biosci., 7: d808 - 826

Santoro, M., Begli Uberti, B., Galiero, G., Di Prisco, F., Alessio, N.D., VeneZIANO, V. (2013): Chaunocephalus ferox (Digenea: Echinostomatidae) infection associated with fatal cachexia in a white stork (Ciconia ciconia). Helminthologia, 50(3): 181 - 184. DOI: 10.2478/s11687-013-0129-z 
SEY, O. (1965): Studies on endoparasitic helminths of Hungary. Acta Acad. Paedag. Civ. Pecs, 9: 179 - 199

Schuster, R., Schaffer, T., Shimalov, V. (2002): Die Helminthenfauna einhemisher Weisstörche (Ciconia ciconia). Berl. Munch. Tierarztl. Wochenschr., 115: 435 - 439

Sitko, J., Heneberg, P. (2015). Composition, structure and pattern of helminth assemblages associated with central European storks (Ciconiidae). Parasitol. Int., 64: 130 - 134. DOI: org/10.1016/j. parint.2014.11.004
TURK, D.E. (1982). Symposium: The avian gastrointestinal tract and digestion. The anatomy of the avian digestive tract as related to feed utilization. Poultry Sci., 61: 1225 - 1244

Zhrtova, O.P., Korol, E.M. (2012): Cathaemasia hians (Digenea, Cathaemasiidae) from Planorbis planorbis (Mollusca, Gastropoda) in reservoirs of central Polissya. Vest. zool., 46(4): e-42 - e-45. DOI: 10.2478/v10058-012-0029-6 